\title{
A systematic review of the trade show marketing literature: 1980-2014
}

Wondwesen Tafesse

Postdoctoral Researcher in Marketing

UIT - the Arctic University of Norway

School of Business and Economics

Post box 6050 Langnes

9037 Troms $\varnothing$, Norway

Telephone: (+47) 77620815

Email: wondwesen.tafesse@uit.no

Kåre Skallerud (corresponding author)

Professor in Marketing

UIT - the Arctic University of Norway

School of Business and Economics

Post box 6050 Langnes

9037 Troms $\varnothing$, Norway

Telephone: (+47) 77646820

Email: kare.skallerud@uit.no 


\begin{abstract}
The trade show marketing literature has been growing over the past decades, attracting a steady stream of research and journal publications. However, this body of research has not been subject to a systematic literature review. Accordingly, the purpose of this article is to provide a systematic review of the trade show marketing literature with the aim of delineating its current state, trends, gaps and inconsistencies. To this end, multiple electronic databases were searched and 91 trade show articles published in 24 marketing journals were extracted. The extracted articles were carefully analyzed with the help of a comprehensive classification framework focusing on broad thematic, theoretical and methodological dimensions. The findings revealed that: (a) trade show research is marked by inconsistencies that concern core thematic issues, such as trade show participation modes, trade show activity stages and trade show performance; (b) trade show research is atheoretical for the most part, but has become increasingly theory oriented in recent years; and (c) trade show research is heavily dependent on a combination of cross-sectional designs and surveys, with limited application of other designs and data collection approaches. Building on these findings, the review proposes an extensive research agenda to help move the trade show marketing literature forward.
\end{abstract}

Key words Trade show; Trade fair; Exhibition; B2B marketing; Literature review 


\section{Introduction}

Trade shows date back to biblical times. An international trade show that took place in Damascus, Syria is cited in the Old Testament (Ezekiel, 27: 12-24). The development toward the contemporary trade show format began in Germany in the 1850s (Kallman, 1988) and the first significant international trade show was organized in Crystal Pallace, in 1851, drawing exhibitors from 72 countries (Short, 1967). In the US, trade events can trace their roots to the completion of the Chicago International Exposition Building in 1872 (Herbig \& Palumbo, 2002). These and other early trade shows served a useful purpose by stimulating commerce and creating market access to local products (Gopalakrishna \& Lilien, 2012).

Today, trade shows constitute an integral element of the industrial marketing process (Rinallo et al., 2016). Trade shows represent recurrent business events that facilitate various forms of commercial and social exchanges among key stakeholders of an industry (Tafesse \& Skallerud, 2015). Manufacturers, suppliers, organizational buyers, distributors, industry associations, regulators and government departments all attend trade shows, albeit with different motivations and objectives (Rosson \& Seringhaus, 1995). The diversity and concentration with which trade shows draw together powerful industry actors create a lively environment, where transactions can be conducted, market information can be exchanged and inter-organizational relationships and networks can be initiated and revitalized (Blythe, 2002; Rice, 1992). This unique capability of trade shows in facilitating a simultaneity of exchanges has attracted considerable interest from marketing scholars and a steady stream of journal articles has been published on the topic over the past decades (Tafesse \& Skallerud, 2015).

Despite this, however, academic research still struggles to answer the most basic questions: why organize, exhibit at, and visit trade shows? The trade show marketing literature is characterized by uncoordinated efforts and a patchy collection of answers (Gopalakrishna \& Lilien, 2012). One possible reason for this lack of clear conclusions might 
be the paucity of efforts aimed at synthesizing available research findings. Although a handful of reviews exist, these reviews do not provide a comprehensive treatment of the trade show marketing literature (e.g., Seringhaus \& Rosson, 1994; Shoham, 1999). The reviews typically address narrow thematic issues, such as trade show planning (Seringhaus \& Rosson, 1994) and trade show performance (Hansen, 2004; Shoham, 1999), but rarely outline broader issues in the literature. The reviews are also limited in their coverage, failing to identify and evaluate all available primary studies. Overall, the trade show marketing literature conspicuously lacks a comprehensive and systematic literature review. Due to the rather piecemeal approach of previous reviews, a comprehensive and systematic review would be highly beneficial at this stage in the field's development.

To this end, this article reports on the results of the first-ever systematic review of the trade show marketing literature. The review begins by developing a classification framework that allows for a systematic comparison and analysis of the trade show marketing literature based on broad thematic, theoretical and methodological dimensions. This is followed by an exhaustive search of journal articles via multiple electronic databases, which identified 91 articles, published between 1980 and 2014, in 24 marketing journals. The review then carefully analyzed and coded the extracted articles and summarized their findings using the proposed classification framework. The findings discern what has been accomplished so far in the trade show marketing literature, and what theories and methods have been used. The findings further reveal how the literature has evolved over time in terms of key thematic interest and core theoretical and methodological orientations. Building on these findings, and in light of the gaps and inconsistencies found in the literature, the review develops an extensive research agenda. By identifying the most important themes and trends in trade show research, the review draws together useful implications for future research. 
The remainder of the paper is structured as follows. Section two provides an overview of trade shows focusing on their definition, typology and role in the industrial marketing process. Section three details the review procedure, which is followed by a discussion of the main findings in section four, and a summary of major theoretical and managerial implications in section five.

\section{Trade shows: an overview}

Trade shows are formally defined as "market events of a specific duration, held at regular intervals, at which a large number of companies present the main product range of one or more industry sectors" (Kirchgeorg et al., 2010, p. 63). Trade shows constitute a highly concentrated market system, where a large assortment of sellers, buyers, suppliers, distributors and intermediaries are gathered in one place, for a specific period of time, creating a fertile ground for rich, face-to-face interactions (Rice, 1992; Rosson \& Seringhaus, 1995). Trade shows are designed to promote sales, build relationships and facilitate knowledge exchange simultaneously (Blythe, 2002; Ling-yee, 2006).

Trade shows are often classified into multiple typologies. Following their industry profile, trade shows are classified into vertical vs. horizontal. Whereas vertical shows typically exhibit a narrow product range, horizontal shows exhibit a wider product range, often derived from multiple industrial sectors (Wu et al., 2008). Following their visitor profile, trade shows are classified into industrial vs. consumer. Whereas industrial shows primarily target professionals and organizational buyers, consumer shows primarily target individual consumers and the public at large (Tafesse, 2014). There are also mixed shows that cater to both professional and consumer visitors, often by devising separate attendance schedules (Palumbo \& Herbig, 2002). Finally, following the geographic origin of their 
participants, or more broadly, market coverage, trade shows are classified into international, national and regional (Seringhaus \& Rosson, 1994).

The trade show typology forms an important consideration set in the trade show decision process (Shoham, 1992). Because different trade shows facilitate different interaction environments, participants rely on the trade show typology to make their go/no-go decision, as well as select a specific show to attend (Kijewski et al., 1993). However, growing competition in the trade show industry has led to the proliferation of highly specialized trade shows (Berne \& Gracia-Uceda, 2008). Although horizontal trade shows are still prevalent in certain contexts (e.g., emerging markets), the trend in the leading markets has been toward greater differentiation (Rice \& Almossawi, 2002).

Trade shows are an integral element of the industrial marketing process (Sridhar et al., 2015). In a recent US survey (Forrester, 2014), senior marketing executives indicated that they allocated 20 percent of their total marketing budget to trade shows, ahead of any other media in the marketing mix, including digital advertising (second at 13 percent) and content marketing (third at 12 percent). Because trade shows combine elements of personal selling (e.g., sales people staffing booth stands), advertising (e.g., product display, brochures), and live communication (e.g., product experience, entertainment), they help exhibitors pursue multiple marketing objectives simultaneously, such as creating product awareness, establishing customer relationships and influencing purchase decisions (Blythe, 2002; Tanner, 2002). By combining direct, personalized encounters with hands-on product experiences, trade shows create a lively environment for B2B- interactions (Kirchgeorg et al., 2010). Trade shows are also relatively cost-effective, as they create access to a high volume of interested prospects (Smith et al., 2004).

From the buyers' perspective, trade shows create a unique opportunity to find and connect with relevant suppliers (Borghini et al., 2006; Godar \& O’Connor, 2001). Because 
trade shows bring together a large number of competing suppliers at a single venue, organizational buyers have the opportunity to contact and evaluate several alternative suppliers (Bello, 1992; Blythe, 2002). Research shows that organizational buyers tend to first search for technical information to better understand their buying needs and to formulate alternative product solutions. Once the buying needs are better defined, attention shifts to further considerations, such as price, delivery time, customer service and supplier reputation (Bello, 1992; Borghini et al., 2006). Trade shows offer an excellent platform to evaluate potential suppliers against the complex procurement criteria of organizational buyers (Jackson et al., 1987; Moriarty \& Spekman, 1984). Trade shows are also ideal for reinforcing existing supplier contacts and developing new ones (Blythe, 2002). Trade shows are recognized as "a venue to discern a mutual interest between buyers and sellers and to start future cooperative action" (Godar \& O’Connor, 2001, p. 81). Trade shows bridge the physical, social and technological distance between organizational buyers and sellers and facilitate learning and inter-firm cooperation (Ling-yee, 2006).

In summary, trade shows confer considerable benefits to both industrial buyers and sellers, which explains their continued success in the marketplace, even as new forms of media proliferate the industrial marketing landscape (Rinallo et al., 2016; Sridhar et al., 2015). Having provided an overview of trade shows and their role in the industrial marketing process, we now turn to the substantive details of the review. We begin by outlining our review procedure.

\section{Review methodology}

The present review follows the well-established tradition of a systematic literature review, which is defined as "a means of identifying, evaluating and interpreting all available research relevant to a particular research question, or topic area or phenomenon of interest" 
(Kitchenham, 2004, p. 1). The principal concern of a systematic literature review is to summarize primary empirical evidence on a particular topic area using an unbiased and objective review procedure (Torraco, 2005).

The current review specifically targeted peer-reviewed journals, which constitute the principal publication outlet for academic research on trade shows. The review further targeted trade show articles published in marketing journals. Marketing is arguably the first discipline to delineate trade shows as a specialized research domain. By focusing on the trade show marketing literature, we intend to capitalize on the wealth of insights that have accumulated over the years. Nevertheless, one can also find a growing body of trade show research in other disciplines, especially in tourism (e.g., Jin \& Weber, 2013; Whitfield \& Webber, 2011) and economic geography (e.g., Maskell et al., 2006; Rinallo \& Golfetto, 2011). While the trade show research in tourism tends to adapt ideas and concepts drawn from the wider tourism and marketing literature, the trade show research in economic geography draws on concepts such as "event-based business networks" (Hedaa \& Törnroos, 2008) and "temporary spatial clusters" (Rinallo \& Golfetto, 2011). Trade shows are conceived as temporary clusters that foster organized proximity among industry actors who are otherwise geographically and technologically distant (Power \& Jansson, 2008). These temporary clusters are characterized by knowledge-exchange mechanisms and relational spaces comparable to that of permanent clusters (Maskell et al., 2006). Although our exclusive focus on the trade show marketing literature precludes a multi-disciplinary review, this was deemed necessary due to both analytical and space constraints.

Finally, the review targeted articles published after 1980. The pattern of trade show publications before 1980 was largely erratic. The literature search reveals that it was mainly after 1980 that trade shows began to attract sustained academic research. For this reason, our sample included trade show articles published between 1980 and 2014. 
To extract pertinent articles, the authors explored multiple electronic databases including ABI/INFO, ProQuest, Scopus, Science Direct and Web of Science. These databases were searched for articles containing "trade show," "trade fair" and "exhibition" in their titles, keywords or abstracts. These are terminologies that are widely and interchangeably used in the trade show marketing literature (Palumbo \& Herbig, 2002). As Kirchgeorg et al. (2010) noted, "the term 'trade show' is regarded as a synonym for fairs, trade fairs and exhibitions" (p. 63). After dispensing with articles published in non-marketing journals and works published through non-journal outlets (e.g., conference papers, books, reports), 91 eligible trade show articles were obtained ${ }^{1}$. Copies were retrieved from electronic databases, online journal archives, physical libraries, as well as the authors' personal collection.

In order to synthesize the extracted articles, the authors developed a comprehensive classification framework focusing on broad thematic, theoretical and methodological dimensions. The thematic dimension was denoted by trade show participation modes, trade show activity stages and trade show performance, which span the principal thematic interest of the trade show marketing literature. The theoretical dimension was denoted by a theoretical perspective and theoretical contribution. These two theoretic criteria offer useful indications as to the theoretical status and evolution of the trade show marketing literature. Finally, the methodological dimension was denoted by research design and data collection, which help to clarify key methodological traditions in the trade show marketing literature. Subsequently, the classification framework was translated into a detailed coding instrument. The dimensions and sub-dimensions of the classification framework were converted into layers of coding variables. To ensure robustness, the authors discussed the coding variables and developed working definitions for each. Actual coding involved the authors reading the main body of the extracted articles and coding them into applicable coding variables. When coding was

\footnotetext{
${ }^{1}$ Basic bibliographic details of the extracted articles are summarized in an appendix, which is available upon request.
} 
completed, an SPSS data file was created and the coded data was analyzed appropriately. The following section discusses the results of these analyses and their theoretical and practical implications.

\section{Findings}

For analytical purposes, the extracted articles were grouped into seven publication periods, each spanning a five-year interval. As shown in Table 1, the number of articles was meagre during the first two publication periods, but recorded considerable growth during the third (1990-1994) and fourth (1995-1999) publication periods. The number of articles then slightly declined during the fifth (2000-2004) and sixth (2005-2009) publication periods, but peaked during the last publication period (2010-2014). In terms of journal distribution, 24 marketing journals are represented in total, with Industrial Marketing Management and Journal of Business \& Industrial Marketing accounting for more than 40 percent of the extracted articles. The next sizable batch of articles appeared in International Marketing Review, Journal of Business Research and Journal of Promotion Management, which published five articles each. Table 1 reports the complete journal distribution of the extracted articles.

\section{Table 1 about here}

\subsection{Trade show participation modes}

Trade shows attract a diverse group of both core (e.g., manufacturers, suppliers, buyers, consumers, distributors and service providers) and peripheral market actors (e.g., industry associations, industry experts, regulators) (Rice, 1992; Rosson \& Seringhaus, 1995). These market actors participate at trade shows through one of three modes: the exhibiting mode, the 
visiting mode or the organizing mode. Each of these participation modes entails distinct approaches in terms of pertinent goals, actions and outcomes.

The exhibiting mode requires participants to set up physical exhibits, where they display their products and solutions and establish face-to-face contacts with current and prospective customers (Gopalakrishna \& Lilien, 1995). In the visiting mode, firms typically dispatch a group of personnel to a prescreened trade show to evaluate potential suppliers, gather market information or build network connections (Godar \& O'Connor, 2001). Finally, in the organizing mode, firms manage the trade show event itself, which entails planning and implementing various creative, marketing and logistical activities (Dawson et al., 2014).

Table 2 reports the distribution of articles among the three participation modes. About 66 percent of the articles studied the exhibiting mode, 16 percent of the articles studied the visiting mode, while only four percent of the articles studied the organizing mode. The remaining 13 percent of the articles studied multiple participation modes, mostly the exhibiting and the visiting modes. Looking at the trend over time, the proportion of articles devoted to the exhibiting mode declined from about 76 percent in the 1990s to about 45 percent in the 2010-2014 period, whereas the proportion of articles devoted to the visiting mode fluctuated throughout the review period. On the other hand, all four articles devoted to the organizing modes were published during the 2010-2014 period. Likewise, a considerable number of those articles that studied multiple participation modes were published during the 2010-2014 period.

\section{Table 2 about here}

Although Table 2 offers evidence of a diversifying body of trade show research, the exhibiting mode remains deeply entrenched in the literature. The concentration of articles in the exhibiting mode might have to do with established theoretical predispositions. Because the 
exhibiting mode constitutes the supply side of the trade show market system (i.e., manufacturers, suppliers, service providers, etc.), it lends itself well to the application of received marketing management theories, such as market orientation, relationship marketing and the marketing/promotion mix concept.

Nevertheless, the visiting and the organizing modes present equally exciting research opportunities. Visitors, for instance, constitute the demand side of the trade show market system (i.e., buyers, customers, consumers, etc.), and they are shown to engage in a variety of rational, emotional and creative behavior during their trade show visit (Ahola, 2012; Borghini et al., 2006). Likewise, organizers represent service providers that draw together sophisticated networking and partnership capabilities, and a deeper industry awareness (Munuera \& Ruiz, 1999; Tafesse, 2014). Organizers typically set the trade show agenda, screen prospective participants and configure the layout of the exposition, giving them immense power in shaping the trade show environment (Dawson et al., 2014; Tafesse, 2014). These dynamics suggest that the visiting and the organizing modes offer a rich empirical setting for marketing research. Theories from consumer behavior, marketing management and organizational studies could be tested, refined and extended based on the visiting and the organizing modes. Although such efforts have been attempted in the past (e.g., Dawson et al., 2014; Gottlieb et al., 2011), and some studies are found in the literature that addressed the buying behavior of non-industrial actors (e.g., Tafesse \& Korneliussen, 2012), there is still a considerable scope for more research.

Another notable inconsistency is the poor representation of trade show participants consisting of industry associations, consultants, regulators, government bodies and research institutions. Although these participants mainly represent peripheral market actors, as they lack direct market involvement, they nonetheless add a useful dimension to the trade show environment (Tafesse \& Skallerud, 2015). First, their industry embeddedness means that 
peripheral market actors bring in tacit and experiential industry knowledge that serves to enrich the interaction environment at trade shows (Rice, 1992; Rinallo \& Golfetto, 2006). Second, and owing mainly to their enhanced political position, peripheral market actors can act as sources of legitimacy and resources, especially in new market contexts (Dawson et al., 2014; Tafesse, 2014). Although calls were made in the past to view trade shows as "networks of connected exchange relationships $[\ldots]$ and microcosms of industries $[\ldots]$ with a multitude of buyers and sellers, service providers, partners, industry and regulatory bodies" (Rosson \& Seringhaus, 1995, p. 87), this perspective is largely underdeveloped in the trade show

marketing literature. As such, placing more emphasis on peripheral market actors could greatly benefit the literature by expanding its theoretical scope and producing a fuller picture of the interaction dynamics at trade shows (Borghini et al., 2006). In this regard, perspectives developed in the economic geography literature could provide a useful impetus. With its emphasis on spatial networks and knowledge exchanging mechanisms, the economic geography literature can lend an expanded theoretical lens through which the role of peripheral market actors could be fruitfully studied (Maskell et al., 2006; Rinallo et al., 2016).

\subsection{Trade show activity stages}

Trade show participants plan and implement their activities using a three-stage temporal framework, consisting of pre-show, at-show and post-show stages. These three activity stages have distinct purposes within the overall scheme of the trade show campaign (Rosson $\&$ Seringhaus, 1995; Tanner, 2002). The pre-show stage represents the planning phase before the start of the show, the at-show stage represents the live-action/execution phase during the show, and finally, the post-show stage represents the follow-up phase after the show (Gopalakrishna \& Lilien, 2015).

Table 3 reports the distribution of articles among the three activity stages. About 32 percent of the articles in the sample studied at-show activities. Among key areas of emphasis 
are booth staff behavior, booth configuration and product presentation (exhibitors' perspective); information search, supplier evaluation and product experiences (visitors' perspective). About eight percent of the articles studied pre-show activities, focusing on issues such as trade show objectives, trade show selection, budgeting practices, staffing decisions and pre-show promotion. However, trade show activity stages are mainly studied in conjunction. About 60 percent of the articles in the sample studied two or more activity stages simultaneously (e.g., pre-show and at-show stages; pre-show, at-show and post-show stages).

\section{Table 3 about here}

Despite a large percentage of articles devoted to multiple activity stages, little corresponding knowledge has emerged on how these activities interact and work together. The typical approach has been to tabulate specific tactics employed during each stage separately, with little attention paid to their interaction process. An exception is Gopalakrishna and Lilien's (1995) multi-stage selling approach and subsequent studies that built on it (e.g., Dekimpe et al., 1997; Sridhar et al., 2015). According to this approach, the three activity stages interact with each other to achieve optimal sales performance. The preshow stage employs attention-getting tactics to attract a targeted audience; the at-show stage employs trained booth staff and an elaborate booth design to establish contact with part of the attracted audience; and the post-show stage employs follow-up tactics to foster connections with the contacted audience. Thus, the three activity stages culminate in qualified leads as the final outcome. Nonetheless, this approach is primarily interested in outcome integration rather than process integration. In other words, the framework does not address the organizational mechanisms and processes used to integrate the three activity stages into a coherent marketing strategy. What specific processes and approaches do firms apply to implement an integrated trade show campaign? Do trade show campaigns that benefit from these processes and 
approaches produce more effective outcomes? These are managerially and theoretically valuable questions that need to be addressed in future research.

Another inconsistency concerns the imbalance in terms of the amount of effort devoted to the three activity stages. The relatively greater attention afforded to the at-show stage could be attributed to the traditional sales bias of prior research. When onsite sales are deemed a priority, activities encompassing product presentation, booth configuration and booth staff behavior — all tied to the at-show stage — become critical factors (Bello, 1992; Tanner, 2002). However, the focal orientation of trade shows appeared to have shifted over the years, such that onsite sales are now viewed as ancillary to strategic exchanges and relationships (Geigenmuller, 2010; Sarmento et al., 2015a). This development should be helpful to bring the pre-show and post-show stages to the forefront of trade show research. For instance, the pre-show stage, owing to its temporal primacy, could be valuable to the trade show integration process. Through careful planning, resource allocation and staffing decisions, firms could imbue their trade show campaigns with strategic marketing priorities (Berne \& Gracia-Uceda, 2008; Kijewski et al., 1993). Likewise, the post-show stage, owing to its temporal recency, could be indispensable to institutionalize the commercial and social ties initiated at trade shows (Bettis-Outland et al., 2010). In fact, actions taken at the post-show stage are shown to be crucial in crystalizing and exploiting opportunities identified at trade shows (Rice, 1992; Smith et al., 2004). Thus, according greater emphasis to the pre-show and post-show stages might lead to a deeper appreciation of the strategic value and contribution of trade shows.

\subsection{Trade show performance}

Trade show performance seeks to quantify the success of trade show efforts and ascertain their economic payoffs (Shoham, 1999). Trade show performance is a construct that measures how effectively and efficiently firms are able to accomplish their pre-specified trade 
show objectives (Hansen, 2014). The measurement of trade show performance involves developing quantitative metrics that link well-defined trade show objectives to managerially relevant trade show outcomes (Hansen, 2004). When done properly, trade show performance generates actionable insights that help decision makers to tie key trade show objectives with specific organizational actions and resources (Sridhar et al., 2015).

In the literature, trade show performance is distinguished into sales-related versus behavior-related (Hansen, 2004). Sales-related performance assesses the extent to which trade show efforts result in selling outcomes (Gopalakrishna \& Williams, 1992). Sales-related performance relies on such metrics as booth attraction efficiency, booth conversion efficiency, lead efficiency and actual sales (Dekimpe et al., 1997; Gopalakrishna \& Lilien, 1995; Smith et al., 2014), which are computed using data from participants' trade show efforts, and are readily comparable across firms (Gopalakrishna \& Williams, 1992). However, their narrow focus on selling outcomes often constrain their applicability to non-selling outcomes. On the other hand, behavior-related performance assesses the extent to which trade show efforts result in behavior-related (non-selling) outcomes, such as industry/market information, customer/supplier relationship and image building, among others (Hansen, 2004; Kerin \& Cron, 1987). Behavior-related performance often relies on informants' self-reported performance evaluation on a multi-response scale (e.g., 1 = very poor, $5=$ excellent), where higher scores generally indicate better performance, but comparison across firms could prove problematic due to the subjective nature of the resulting scores.

As shown in Table 4, about 44 percent of the articles in the sample $(n=40)$ incorporated performance measurement. Of these, 90 percent are focused on the exhibiting mode, eight percent are focused on the visiting mode, while only two percent are focused on the organizing mode. In the exhibiting mode, both sales-related and behavior-related metrics are employed (e.g., Dekimpe et al., 1997; Lee \& Kim, 2008), while in the visiting mode, only 
behavior-related metrics are employed (e.g., Gottlieb et al., 2014; Smith et al., 2003), and in the organizing mode, only sales-related metrics, based on exhibitor and visitor traffic, are employed (Tafesse, 2014).

Looking at the trend, behavior-related metrics have become increasingly popular, accounting for 36 percent of the articles during the 2010-2014 period, while sales-related metrics accounted for just five percent of the articles during the same period. This shift in performance measurement appears to reflect the growing prominence of non-selling outcomes at trade shows, such as customer/supplier relationship, information gathering and image building (Blythe, 2002; Hansen, 2004; Ling-yee, 2006).

\section{Table 4 about here}

A major area of concern is the skewed distribution of trade show performance across the three participation modes. While some three dozen articles measured trade show performance in the exhibiting mode, only a handful of articles measured trade show performance in the visiting and the organizing modes. This has contributed to a situation where little systematic insight has formed about trade show performance in relation to the visiting and the organizing modes. A gap exists in the understanding and measurement of trade show performance from multiple perspectives. This inconsistency points to the need to develop managerially relevant and conceptually sound performance metrics focused on the visiting and the organizing modes. For instance, satisfaction is a well-developed theoretical concept in the wider marketing literature and can serve as a good summary measure of visitors' activities at trade shows (Gottlieb et al., 2011). Likewise, metrics involving attendance growth, proportion of new (repeat) attendance, and changes in market share and profitability can serve as a useful measure of performance in the organizing mode (Tafesse, 2014). Advances in the development of relevant performance metrics can inspire sophisticated empirical models 
linking specific organizational tactics and approaches to visitors' and organizers' performances.

\subsection{Theoretical perspective}

The theoretical perspective captures the extent to which trade show research applies theories, conceptual frameworks and models to motivate and guide its investigations. Theories, conceptual frameworks and models provide a useful analytical lens through which pertinent research problems can be framed and sound variables and propositions can be developed and tested (Maclnnis, 2011; Sutton \& Staw, 1995). A robust application of theory contributes to a systematic accumulation of knowledge through an organized process of validating, extending and expanding a field's knowledge base (Colquitt \& Zapata-Phelan, 2007)

The current review examined the extent to which trade show articles employ explicitly stated theories, conceptual frameworks and models. For this purpose, both broader marketing and organizational theories and specialized trade show frameworks and models were considered. As shown in Table 5, half of the articles in the sample $(n=46)$ are atheoretical, thus lacking any discernable theoretical development; whereas the remaining half of the articles $(n=45)$ made explicit use of theoretical perspectives. Looking at the trend, the proportion of articles grounded in specific theoretical perspectives has witnessed remarkable growth, reaching 86 percent during the $2010-2014$ period. Thus, although prior trade show research was largely atheoretical, recent contributions have become increasingly theory oriented. 
Moreover, as shown in Table 6, the theoretically grounded articles draw upon 22 different theoretical perspectives. Theories from consumer behavior (e.g., consumer culture theory, shopping behavior), marketing management (e.g., relationship marketing theory, services marketing theory, the promotion mix concept) and organizational studies (e.g., RBV, inter-organizational network theory, role theory), are all represented in trade show research. The fact that such a variety of perspectives are invoked in trade show research speaks to the relative complexity, as well as richness of the trade show phenomenon. The use of a wide spectrum of theoretical perspectives contributes different ideas and provides multiple layers of explanation to important issues. However, this apparent case of theoretical diversity could also signal the lack of a consolidated conceptual foundation. Indeed, researchers are more prone to borrow theories from external sources than to apply theories from within. We could only identify five instances where specialized trade show conceptual frameworks and models were employed in the literature (e.g., Lee \& Kim, 2008; Skallerud, 2010). To be sure, the use of external theories is a worthwhile effort, as it could contribute to the topicality and relevance of trade show research (Zahra \& Newey, 2009). However, it needs to be complemented with a focus on trade show specific frameworks and models, in order for the literature to be consolidated into a solid knowledge base. For this reason, research focused on testing, extending and integrating specialized trade show models and frameworks should be welcomed.

\section{Table 6 about here}

Also notable is the evolutionary trend of theory use in the trade show marketing literature. In particular, theories such as relationship marketing theory, market orientation, RBV and services marketing theory have gained in popularity in recent years. The growing prominence of strategic marketing perspectives is consistent with the increasingly strategic 
role performed by trade shows (Geigenmuller, 2010). A similar trend is observed in the application of interpretive consumer behavior theories, such as consumer culture theory and experiential marketing approach, which is a testament to the increasing experiential prowess of trade shows (Ahola, 2012; Rinallo et al., 2010). There are also theoretical perspectives that have weakened over the years. A case in point is the new product development/diffusion perspective, which was prominent in prior research (e.g., Barczak et al., 1992; Bello \& Barczak, 1990), but has since fallen out of favor. Notwithstanding this theoretical trend, exhibitors and visitors still place strong emphasis on discovering innovative products at trade shows (Borghini et al., 2006; Rinallo \& Golfetto, 2006). As Sarmento et al. (2015a) noted recently, "presentation of new products, and therefore, product innovation has been amongst the most important factors for trade show attractiveness [...] Many participants continue to go to the trade fair searching for product novelty" (p. 589). Thus, it seems that the new product development/diffusion perspective needs to be revitalized in light of the continued importance of discovering new products at trade shows (Ahola, 2012). Likewise, the limited use of firm internationalization theory was unexpected. Trade shows are often lauded for their "contribution to establishment and enhancement of a network infrastructure which enable firms to grow and expand internationally" (Evers \& Knight, 2008, p. 553). One possible reason for this trend could be the underrepresentation of international trade shows as an empirical setting, where internationalization efforts are likely to be amplified. Regardless, the declining use of firm internationalization theory deserves closer scrutiny, given the longstanding contribution of trade shows to the export development process (Seringhaus \& Rosson, 1998),

\subsection{Theoretical contribution}

Theoretical contribution captures the extent to which trade show articles add novel and substantive theoretical insights to the extant literature. Theoretical contribution is 
distinguished into three types: exploratory, theory testing and theory building (Colquitt \& Zapata-Phelan, 2007; De Vaus, 2006). Exploratory articles explore core facts and parameters, but lack a discernable theoretical guidance. Theory testing articles, on the other hand, possess a clear theoretical guidance, while also incorporating empirical tests. Finally, theory building articles employ inductive approaches to advance novel concepts, constructs or theoretical relationships. According to Colquitt and Zapata-Phelan (2007), "an empirical article can offer a strong theoretical contribution by being strong in theory building, strong in theory testing, or strong in both" (p. 1282). Hence, a research field can accumulate knowledge faster and more systematically by attracting a greater proportion of theory testing and theory building articles (Zahra \& Newey, 2009).

Table 7 reports analysis of the articles according to their theoretical contribution. Exploratory articles accounted for about half of the articles in the sample $(n=47)$. Most of these articles are focused on "how to do it," practical guidance, and do not offer generalizable theoretical insights. However, some exploratory articles carefully synthesized multiple data sources and insights to develop useful conceptual and measurement models. Notable examples are Kerin and Cron (1987), who combined managerial insights with available research findings to propose a pioneering empirical model of trade show effectiveness; and Rosson and Seringhaus (1995), who collated secondary data from multiple industry sources to propose a model of trade shows as networks of connected exchange relationships.

\section{Table 7 about here}

Articles with theoretical contributions accounted for the remaining half of the articles in the sample $(n=44)$. Of these, 64 percent $(n=28)$ contributed to the literature through theory testing efforts. Typically, these articles derive hypotheses from existing theories and literature sources and subsequently test them on a trade show dataset. The remaining 36 percent $(\mathrm{n}=$ 
16) contributed to the literature through theory building efforts. These articles develop novel frameworks, conceptual models and constructs. Examples include Bettis-Outland et al. (2010) who proposed a model of information use in a trade show context and Gopalakrishna and Lilien (1995) who developed a multi-stage selling framework for exhibitors at industrial trade shows.

Looking at the trend, the share of articles with theoretical contributions has increased considerably, from 28 percent during the 1990-1994 period to 72 percent during the 20102014 period. This development points to the growing efforts in the literature to expand the trade show knowledge base. Moreover, this shift toward substantive theoretical contributions overlaps with the shift toward theoretically grounded research, as discussed in section 4.4. Together, these two findings offer preliminary evidence as to the expanding theoretical scope of the trade show marketing literature. At present, an increasing proportion of trade show articles is grounded in theory and contributes to knowledge primarily through theory testing and theory building efforts.

\subsection{Research design}

Research design is a roadmap that defines the logic and structure of empirical research (Churchill \& Iacobucci, 2005). Research design offers a strategy to generate reliable data, such that the evidence obtained can answer the questions that motivated the research as unambiguously as possible (De Vaus, 2006). Five distinct research design approaches were identified in the methodology literature: experimental, longitudinal, cross-sectional, casestudy and comparative. The empirical component of the extracted articles $(n=73)$ is analyzed according to these approaches. Table 8 summarizes the findings.

\section{Table 8 about here}


Cross-sectional design accounts for 74 percent of the empirical articles in the sample, which makes it by far the most popular in trade show research. Case-study design is a distant second, accounting for 10 percent of the empirical articles. Comparative design is a close third, accounting for eight percent of the articles. The remaining design approaches account for 4 percent of the articles each. Looking at the trend, cross-sectional design remains deeply entrenched in the trade show marketing literature, accounting for well above 70 percent of the empirical articles throughout the review period.

The dependence of trade show research on cross-sectional design appeared to have resulted in a leaner application of other design approaches. Clearly, a more diverse application of research design would have benefited the trade show marketing literature by expanding its theoretical scope, as well as empirical rigor. Indeed, some of the thematic inconsistencies highlighted in earlier sections could, in part, be attributed to the poor diversity of research design.

For instance, if cross-sectional design generates a snapshot of a particular phenomenon, longitudinal design offers a temporally extended overview (De Vaus, 2006), making it particularly fitting to the trade show context. Using longitudinal design, researchers could acquire a more complete view of trade shows (Rice \& Almossawi, 2002). With a deeper application of longitudinal design, for instance, it would have been possible to produce more knowledge about the pre-show and post-show stages and their strategic implication. Likewise, cross-sectional design tends to sacrifice depth for breadth, while case-study yields the opposite effect. Consequently, a more intensified application of case-study would have been instrumental in shedding light on complex trade show phenomena, such as organizational learning, channel partnerships and networking (Rice \& Almossawi, 2002). Take, for example, Rinallo and colleagues' ethnographic study of trade shows (Rinallo et al., 2010). Trade shows are usually conceptualized as information sources for industrial buyers (Hansen, 2004), where 
exhibitors provide information about their offerings using a variety of communication tools, including brochures, displays, products, tasting, personal interactions, and so on (Bello, 1992). However, Rinallo et al. (2010) revealed that the environment at trade shows is replete with sensorial stimuli (e.g., sounds, odors, colors, signs, physical objects, the crowd), all of which carry information and compete to attract visitors' attention. To some visitors, this can lead to sensorial overwhelming, information overload and physical fatigue as they are exposed to a barrage of stimuli that they simply cannot cope with. These findings are an excellent illustration of how alternative designs and conceptual models can reveal phenomena that conventional methods (e.g., surveys) fail to recognize.

Trade shows are also expedient for experimental and quasi-experimental designs. For instance, researchers can compare differences based on measurements taken before and after trade show participation. In effect, the trade show participation can be used akin to the treatment effect in classical experiments. This approach appears particularly suitable to capture the impact of trade show participation on awareness and behavioral intention constructs (Smith et al., 2004). Another experimental approach is for researchers to disguise as visitors and observe exhibitors' behavior by simulating different behaviors and actions. An early application of this approach can be found in Tanner (1994).

\subsection{Data collection methods}

Data collection is the second criterion employed to evaluate methodological orientations in the trade show marketing literature. The empirical portion of the articles $(n=73)$ is analyzed for this purpose. Table 9 summarizes the findings.

Table 9 about here 
Survey is by far the most popular data collection method in the trade show marketing literature, accounting for 62 percent of the empirical articles. Survey supplemented with other data collection methods, such as in-depth interviews and secondary data, is a distant second, accounting for 21 percent of the empirical articles. Ethnography accounts for eight percent, while interview and secondary data account for seven and two percent of the empirical articles, respectively. Looking at the trend, the survey has maintained its dominant position throughout the review period.

The overriding popularity of the survey appears to have crowded out other data collection methods. The deployment of multiple data collection methods together with novel data sources would have enhanced the depth and rigor of the trade show marketing literature. Methodological plurality reinforces empirical rigor by facilitating triangulation and off-setting biases inherent in a single method or data source (Johnson \& Onwuegbuzie, 2004).

A case in point is the internet, which is a vital source of data in the trade show industry, but one that is poorly exploited in the trade show marketing literature (Ling-yee, 2010). Organizers, in particular, publish a wealth of exhibitor and visitor statistics on their websites, often going back to a number of editions in the past (Tafesse, 2014). They also assemble refined behavioral data on past editions, which has the dual purpose of internal planning and monetization (i.e., organizers sell the data to customers for better trade show planning) (Friedman, 2013). Access to these sorts of data enable researchers to develop and test frameworks and models that draw on aggregate behavioral data. Social media is another potentially valuable, but underutilized, data source. Trade show organizers are increasingly utilizing social media channels, such as Facebook and Twitter, to provide information about their shows and interact with current and prospective customers on an ongoing basis (Friedman, 2013; Gopalakrishna \& Lilien, 2012). Researchers could exploit these platforms to 
gain a first-hand account of trade show participants' interactive behavior before, during and after the show.

Researchers should also consider the possibility of applying RFID technologies, such as reader devices, tags and electronic ID cards that can track participant movements in real-time (Chongwatpol, 2015). These tracking technologies produce unique spatial and temporal data that can be used to map out major behavioral patterns during trade show visits (Gopalakrishna et al., 2010). Besides their immediate tactical implications (e.g., identify booth locations that maximize visitor traffic or time spent by visitors), such data might also offer vital clues to predict macro trends (e.g., demand for a new product). Recently, Gopalakrishna et al. (2010) applied this method to propose a typology of organizational buyers at industrial trade shows.

It is also important to note that access to the preceding data sources is contingent upon closer collaboration with the industry. Besides generating novel data, therefore, the use of these data sources brings researchers closer to the industry, which, in turn, contributes to the relevance and external validity of trade show research.

\section{Conclusion and Implications}

This article marks the first systematic effort at reviewing the trade show marketing literature. The study covered 91 trade show articles, published in 24 marketing journals, and summarized their approaches and findings based on broad thematic, theoretical and methodological dimensions. In the following, we summarize the key findings of the review along with their implications for theory and practice.

First, the review has examined core thematic issues based on trade show participation modes, trade show activity stages and trade show performance. With respect to trade show participation modes, research is largely concentrated on the exhibiting mode, while the visiting and the organizing modes received only cursory attention. This is counterintuitive 
since all three participation modes are critical for the survival and growth of the trade show industry. This inconsistency suggests the need to support the visiting and the organizing modes with more research in the future (Gopalakrishna \& Lilien, 2012). Also important is an expansion of the scope of trade show research by juxtaposing trade shows as industry microcosms and networks of connected exchange relationships (Rosson \& Seringhaus, 1995). Specifically, the role of peripheral market actors warrants closer attention, where focal concepts and constructs developed in the economic geography literature could provide an expanded theoretical lens (Maskell et al., 2006; Rinallo et al., 2016).

Further inconsistencies concern trade show activity stages. Although a large proportion of articles researched multiple activity stages, little progress has been made in understanding how these activities interact with each other. The typical approach has been to tabulate tactics employed during each activity stage separately. Therefore, a critical research priority should be to explore the organizational mechanisms and processes used to integrate the three activity stages into a coherent marketing strategy. Similarly, as trade shows continue to evolve toward more complex inter-organizational exchanges and relationships, the pre-show and post-show stages are set to grow in influence (Blythe, 2002; Geigenmuller, 2010). This development suggests the need to accord greater attention to the pre-show and post-show stages of the trade show campaign.

The final thematic issue concerns trade show performance, where a highly skewed distribution of performance articles is found. Specifically, knowledge about what constitutes trade show performance in the visiting and the organizing modes and what organizational and trade show related factors influence it are quite limited (Gopalakrishna \& Lilien, 2012). Therefore, an important focus area should be an expansion of the scope of trade show performance by expediting its measurement from multiple perspectives. Researchers are 
encouraged to develop performance metrics that tie well-defined visitor and organizer objectives to managerially relevant trade show outcomes.

Second, the review has examined theoretical issues. The use of theory in the trade show marketing literature is largely encouraging, with a strong upsurge in theory oriented articles and a fairly diversified theoretical underpinning. Of concern, however, is the growing deprioritization of trade show specific frameworks and models. As researchers increasingly prioritize external theories, specialized trade show frameworks and models have taken a back seat, hindering potential consolidation of the literature. Likewise, interest has waned in certain, historically rooted theoretical perspectives, such as new product development/diffusion and firm internationalization theory. The stagnation in these perspectives is largely inexplicable from an industry (managerial practice) point of view, and as such, warrants closer examination in the future (Evers \& Knight, 2008; Sarmento et al., 2015a).

Third, the review has evaluated methodological issues. The findings reveal a skewed distribution favoring a combination of cross-sectional design and survey data. This narrow methodological orientation should motivate more creative efforts in the literature, where novel design approaches and emerging data sources are more rigorously implemented (Rice \& Almossawi, 2002). The use of diverse research design (e.g., interpretive and longitudinal perspectives) and novel data sources (e.g., internet, social media and RFID), contributes to the collective ability to triangulate and cross-validate important findings, in turn improving the rate and quality of theory development in the literature. Although interpretive and longitudinal approaches are still unconventional in the trade show marketing literature, the few available cases produced promising results.

In conclusion, the present article has illuminated the current state and key trends of the trade show marketing literature. However, due to both analytical and space constraints, the 
review had to exclude trade show articles published in the fields of tourism and economic geography. In light of the growing volume of trade show research in these disciplines, failure to include this work is a notable limitation. Despite this, however, we are hopeful that our effort will inspire similar systematic reviews and comparisons of trade show research in tourism and economic geography. In particular, we encourage inter-disciplinary reviews that could bridge the disparate trade show perspectives and approaches in industrial marketing, tourism and economic geography. Future research could benefit from bridging the boundaries between the different domains. For example, Rinallo et al. (2016) provided one of the first attempts to integrate perspectives from both industrial marketing and economic geography. Such efforts are instrumental in cross-fertilizing and synthesizing the divergent theoretical insights and empirical findings toward a shared interpretive paradigm. 


\section{References}

Ahola, E. (2012). Towards an understanding of the role of trade fairs as facilitators of consumer creativity. Journal of Marketing Communications, 18 (5), 321-333.

Barczak, G.J., Bello, D.C., \& Wallace, E.S. (1992). The role of consumer shows in new product adoption. Journal of Consumer Marketing, 9 (2), 55-67.

Bello, D.C., \& Barczak, G.J. (1990). Using industrial trade shows to improve new product development. Journal of Business \& Industrial Marketing, 5 (2), 43-56.

Bello, D.C. (1992). Industrial buyer behavior at trade shows: implications for selling effectiveness. Journal of Business Research, 25, 59-80.

Berne, C., \& Gracia-Uceda, M.E. (2008). Criteria involved in evaluation of trade shows to visit. Industrial Marketing Management, 37 (5), 565-579.

Bettis-Outland, H., Cromartie, J.S., Johnston, W.J., \& Borders, A.L. (2010). The return on trade show information (RTSI): a conceptual analysis”, Journal of Business \& Industrial Marketing, 25 (4), 268-271.

Blythe, J. (2002). Using industrial trade shows for key account management. Industrial Marketing Management, 31 (7), 627-635.

Blythe, J. (2010). Trade fairs as communication: a new model. Journal of Business \& Industrial Marketing, 25 (1), 57-62.

Borghini, S., Golfetto, F., \& Rinallo, D. (2006). Ongoing search among industrial buyers. Journal of Business Research, 59 (10-11), 1151-1159.

Chongwatpol, J. (2015). Integration of RFID and business analytics for trade show exhibitors. European Journal of Operation Research, 244 (2), 662-673.

Churchill, G.A., \& Iacobucci, D. (2005). Marketing research: methodological foundations, Thomson South Western, Mason, Ohio. 
Colquitt, J.A., \& Zapata-Phelan, C.P. (2007). Trends in theory building and theory testing: a five decade study of the Academy of Management Journal. Academy of Management Journal, 50 (6), 1281-1303.

Dawson, B.K., Young, L., Tu, C., \& Chongyi, F. (2014). Co-innovation in networks of resources - a case study in the Chinese exhibition industry. Industrial Marketing Management, 43 (3), 496503.

Dekimpe, M.G., Francois, P., Gopalakrishna, S., Lilien, G.L., \& Van den Bulte, C. (1997). Generalizing about trade show effectiveness: a cross-national comparison. Journal of Marketing, $61(4), 55-64$.

De Vaus, D. (2006). Editor's introduction: research design - a review, in De Vaus, D., Research Design, Sage Publications, London, Thousand Oaks, pp. xxiv-lv.

Evers, N., \& Knight, J. (2008). Role of international trade shows in small firm internationalization: a network perspective. International Marketing Review, 25 (5), 544-562.

Forrester (2014). Focus B2B marketing budget gains on business outcomes to succeed in 2014. Accessed April, 2016, available at:

https://www.forrester.com/report/Focus+B2B+Marketing+Budget+Gains+On+Business+Outcom es+To+Succeed+In+2014/-/E-RES102481

Friedman, F.J. (2013). Future trends impacting the exhibition and events industry. International Association of Exhibitions and Events. IAEE Working Paper.

Geigenmuller, A. (2010). The role of virtual trade fairs in relationship value creation. Journal of Business \& Industrial Marketing, 25 (4), 284-292.

Godar, H.S., \& O’Connor, P.J. (2001). Same time next year - buyer trade show motives. Industrial Marketing Management, 30 (1), 77-86. 
Gopalakrishna, S., \& Williams, J.D. (1992). Planning and performance assessment of industrial trade shows: an exploratory study. International Journal of Research in Marketing, 9 (3), 207224.

Gopalakrishna, S., \& Lilien, G.L. (2012). Trade shows in the business marketing communication mix. In Lilien G. and Grewal R., The Business-to-Business Marketing Handbook, Edward Elgar Press, Cheltenham, pp. 226-245.

Gopalakrishna, S., \& Lilien, G.L. (1995). A three-stage model of industrial trade show performance. Marketing Science, 14 (1), 22-43.

Gopalakrishna, S., Lilien, G.L., Williams, J.D., \& Sequeira, I.K. (1995). Do trade shows pay off?, Journal of Marketing, 59 (3), 75-83.

Gopalakrishna, S., Roster, C.A., \& Sridhar, S. (2010). An exploratory study of attendee activities at business show. Journal of Business \& Industrial Marketing, 25 (4), 241-248.

Gottlieb, U.R., Brown, M.R., \& Drennan, J. (2011). The influence of service quality and trade show effectiveness on post-show purchase intention. European Journal of Marketing, 45 (11-12), $1642-1659$.

Gottlieb, U.R., Brown, M.R., \& Ferrier, L. (2014). Consumer perceptions of trade show effectiveness: scale development and validation within a B2C context. European Journal of Marketing, 48 (1-2), 89-107.

Hansen, K. (2004). Measuring performance at trade shows: scale development and validation. Journal of Business Research, 57 (1), 1-13.

Hedaa, L., \& Tornroos, J. (2008). Understanding event-based business networks. Time \& Society, $17(2 / 3), 319-348$. 
Jackson, D.W., Keith, J.E., \& Burdick, R.K. (1987). The relative importance of various promotional elements in different industrial purchase situations. Journal of Advertising, 16 (4), 25-33.

Jin, X., \& Weber, K. (2013). Developing and testing a model of exhibition brand preference: The exhibitors' perspective. Tourism Management, 38, 94-104.

Johnson, R.B., \& Onwuegbuzie, A.J. (2004). Mixed methods research: a research paradigm whose time has come. Educational Researcher, 33 (7), 14-26.

Kallman, J. (1988). Exhibiting in Germany: Participation without pain. Ideas, April.

Kerin, R.A., \& Cron, W.L. (1987). Assessing trade show functions and performance: an exploratory study. Journal of Marketing, 51 (3), 87-94.

Kijewski, V., Yoon, E., \& Young, G. (1993). How exhibitors select trade shows. Industrial Marketing Management, 22 (4), 287-298.

Kirchgeorg, M., Springer, C., \& Kastner, E. (2010). Objectives for successfully participating in trade shows. Journal of Business \& Industrial Marketing, 25 (1), 63-72.

Kitchenham, B. (2004), "Procedures for performing systematic reviews", Keele University Technical Report TR/SE-0401.

Lee, C.H., \& Kim, S.Y. (2008). Differential effects of determinants on multi-dimensions of trade show performance: by three stages of pre-show, at-show and post-show activities. Industrial Marketing Management, 37 (7), 784-796.

Ling-yee, L. (2006). Relationship learning at trade shows: its antecedents and consequences. Industrial Marketing Management, 35 (2), 166-177.

Ling-yee, L. (2010). Antecedents and effect of internet implementation for trade shows. Journal of Business \& Industrial Marketing, 25 (4), 272-283. 
Maclnnis, D. (2011). A framework for conceptual contributions in marketing. Journal of Marketing, 75 (3), 136-54.

Maskell, P., Bathelt, H., \& Malmberg, A. (2006). Building global knowledge pipelines: The role of temporary clusters. European Planning Studies, 14(8), 997-1013.

Moriarty, R.T, \& Spekman, R.E. (1984). An empricial investigation of the information sources used during the industrial buying process. Journal of Marketing Research, 21 (2), 137-147.

Munuera, J.L., \& Ruiz, S. (1999). Trade fairs as services: a look at visitors' objectives in Spain. Journal of Business Research, 44 (1), 17-24.

Palumbo, F., \& Herbig, P.A. (2002). Trade shows and Fairs. Journal of Promotion Management, $8(1), 93-108$.

Power, D., \& Jansson, J. (2008). Cyclical clusters in global circuits: Overlapping spaced in furniture trade fairs. Economic Geography, 84(4), 423-448.

Rice, G. (1992). Using the interaction approach to understand international trade Shows. International Marketing Review, 9 (4), 32-45.

Rice, G., \& Almossawi, M. (2002). A study of exhibitor firms at an Arabian Gulf trade show. Journal of Global Marketing, 15 (3-4), 149-172.

Rinallo, D., Bathelt, H., \& Golfetto, F. (2016). Economic geography and industrial marketing views on trade shows: Collective marketing and knowledge circulation. Industrial Marketing Management, Available online 19 July.

Rinallo, D., Borghini, S., \& Golfetto, F. (2010). Exploring visitor experiences at trade shows. Journal of Business \& Industrial Marketing, 25 (4), 249-258.

Rinallo, D., \& Golfetto, F. (2011). Exploring the knowledge strategies of temporary cluster organizers: A longitudinal study of the EU fabric industry trade shows (1986-2006). Economic Geography, 87(4), 453-476. 
Rosson, P.J., \& F.H.R. Seringhaus (1995). Visitor and exhibitor interaction at industrial trade fairs. Journal of Business Research, 32 (1), 81-90.

Sarmento M., Farhangmehr, M., \& Simoes, C. (2015a). A relationship marketing perspective to trade fairs: insights from participants. Journal of Business \& Industrial Marketing, 30 (5), 584593.

Sarmento M., Simoes, C., \& Farhangmehr, M. (2015b). Applying a relationship marketing perspective to B2B trade fairs: the role of socialization episodes. Industrial Marketing Management, 44 (1), 131-141.

Seringhaus, F.H.R. \& Rosson, P.J. (1998). Management and performance of international trade fair exhibitors: government stands vs independent stands. International Marketing Review, 15 (5), $398-412$.

Seringhaus, F.H.R., \& Rosson, P.J. (1994). International trade fairs and foreign market involvement: review and research directions. International Business Review, 3 (3), 311-329.

Shoham, A. (1992). Selecting and evaluating trade shows. Industrial Marketing Management, 21 (4), 335-341.

Shoham, A. (1999). Performance in trade shows and exhibitions. Journal of Global Marketing, 12 (3), 41-57.

Skallerud, K. (2010). Structure, strategy and performance of exhibitors at individual booths versus joint booths. Journal of Business \& Industrial Marketing, 25 (4), 259-267.

Smith, T.M., Gopalakrishna, S., \& Smith, P.M. (2004). The complimentary effect of trade shows on personal selling. International Journal of Research in Marketing, 21 (1), 61-76.

Smith, T.M., Hama, K., \& Smith, P.M. (2003). The effect of successful trade show attendance on future interest: Exploring Japanese attendee perspectives of domestic and offshore international events. Journal of Business \& Industrial Marketing, 18 (4), 403-418. 
Sridhar, S., Voorhees, C.M., \& Gopalakrishna, S. (2015). Assessing the drivers of short-and longterm outcomes at business trade shows. Customer Needs and Solutions, 2 (3), 222-229.

Sutton, R.I., \& Staw, B.M. (1995). What theory is not", Administrative Science Quarterly, 40 (3), $371-284$.

Tafesse, W. (2014). Understanding how resource deployment strategies influence trade show organizers performance effectiveness. European Journal of Marketing, 48 (5-6), 1009-1025.

Tafesse, W., \& Korneliussen, T. (2012). Identifying factors affecting consumers purchase incidence at retail trade shows. Journal of Retailing \& Consumer Services, 19 (4), 438-444.

Tafesse, W., \& Skallerud, K. (2015). Towards an exchange view of trade fairs. Journal of Business \& Industrial Marketing, 30 (7), 795-804.

Tanner, J.F. (2002). Leveling the playing field: factors influencing trade show success for small companies. Industrial Marketing Management, 31 (3), 229-239.

Tanner, J.F. (1994). Adaptive selling at trade shows. Journal of Personal Selling \& Sales Management, 14 (2), 15-23.

Torraco, R.J. (2005). Writing integrative literature reviews: guidelines and examples. Human Resource Development Review, 4 (3), 356-67.

Whitfield, J., \& Webber, j. (2011). Which exhibition attributes create repeat visitation? International Journal of Hospitality Management, 30(2), 439-447.

Wong, J., Peng, N., \& Chen, A.H. (2014). Conceptualizing trade show visitors' consumption behavior. International Journal of Tourism Research, 16 (4), 325-328.

Wu, J., Lilien, G.L., \& Dasgupta, A. (2008). An exploratory study of trade show formation and diversity. Journal of Business-to-Business Marketing, 15 (4), 397-424. 
Zahra, S.A., \& Newey, L.R. (2009). Maximizing the impact of organization science: theory

building at the intersection of disciplines and/or fields. Journal of Management Studies, 46 (6), 1059-1075. 


\begin{tabular}{|c|c|c|c|c|c|c|c|c|}
\hline \multirow[b]{2}{*}{ Journal name } & \multicolumn{7}{|c|}{ Publication period } & \multirow[b]{2}{*}{ Total } \\
\hline & $\begin{array}{l}1980- \\
1984\end{array}$ & $\begin{array}{l}1985- \\
1989\end{array}$ & $\begin{array}{l}1990- \\
1994\end{array}$ & $\begin{array}{l}1995- \\
1999\end{array}$ & $\begin{array}{l}2000- \\
2004\end{array}$ & $\begin{array}{l}2005- \\
2009\end{array}$ & $\begin{array}{l}2010- \\
2014\end{array}$ & \\
\hline Industrial Marketing Management & 2 & 1 & 7 & 2 & 3 & 5 & 1 & 21 \\
\hline Journal of Business \& Industrial Marketing & & & 2 & 1 & 1 & 1 & 13 & 18 \\
\hline International Marketing Review & & & 1 & 2 & 1 & 1 & & 5 \\
\hline Journal of Business Research & & & 1 & 2 & 1 & 1 & & 5 \\
\hline Journal of Promotion Management & & & & 1 & 3 & & 1 & 5 \\
\hline Journal of Marketing & & 1 & & 2 & 1 & & & 4 \\
\hline Journal of Marketing Communications & & & & 2 & & & 2 & 4 \\
\hline European Journal of Marketing & & & & & & & 3 & 3 \\
\hline Journal of Global Marketing & & & & 1 & 1 & 1 & & 3 \\
\hline Journal of Marketing Management & & & 1 & & 2 & & & 3 \\
\hline Marketing Intelligence \& Planning & & & & 3 & & & & 3 \\
\hline International Journal of Advertising & & & 1 & 1 & & & & 2 \\
\hline International Journal of Research in Marketing & & & 1 & & 1 & & & 2 \\
\hline Journal of Consumer Marketing & & & 1 & & & 1 & & 2 \\
\hline Journal of Personal Selling and Sales Management & & & 2 & & & & & 2 \\
\hline Academy of Marketing Science Review & & & & 1 & & & & 1 \\
\hline Journal of Business-to-Business Marketing & & & & & & 1 & & 1 \\
\hline Journal of Consumer Research & & & & & 1 & & & 1 \\
\hline Journal of Euro Marketing & & & 1 & & & & & 1 \\
\hline Journal of Historical Research in Marketing & & & & & & & 1 & 1 \\
\hline Journal of Marketing Theory \& Practice & & & & 1 & & & & 1 \\
\hline Journal of Retailing \& Consumer Services & & & & & & & 1 & 1 \\
\hline Journal of Targeting, Measurement \& Analysis for Marketing & & & & & & 1 & & 1 \\
\hline Marketing Science & & & & 1 & & & & 1 \\
\hline Total & 2 & 2 & 18 & 20 & 15 & 12 & 22 & 91 \\
\hline
\end{tabular}


Table 2 Trade show participation modes $(n=91)$

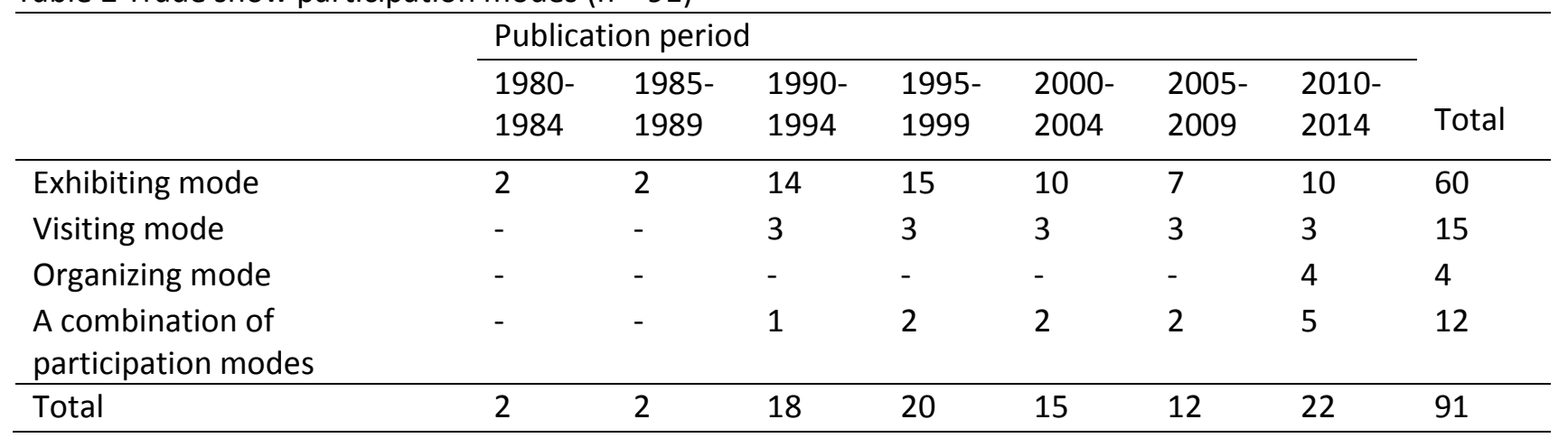

Table 3 Trade show activity stages $(n=91)$

\begin{tabular}{|c|c|c|c|c|c|c|c|c|}
\hline & \multicolumn{7}{|c|}{ Publication period } & \multirow[b]{2}{*}{ Total } \\
\hline & $\begin{array}{l}1980- \\
1984\end{array}$ & $\begin{array}{l}1985- \\
1989\end{array}$ & $\begin{array}{l}1990- \\
1994\end{array}$ & $\begin{array}{l}1995- \\
1999\end{array}$ & $\begin{array}{l}2000- \\
2004\end{array}$ & $\begin{array}{l}2005- \\
2009\end{array}$ & $\begin{array}{l}2010- \\
2014\end{array}$ & \\
\hline Pre-show stage & 1 & - & 3 & - & 1 & 2 & - & 7 \\
\hline At-show stage & - & 1 & 5 & 4 & 6 & 4 & 9 & 29 \\
\hline Post-show stage & - & - & - & - & - & - & - & - \\
\hline $\begin{array}{l}\text { A combination of activity } \\
\text { stages }\end{array}$ & 1 & 1 & 10 & 16 & 8 & 6 & 13 & 55 \\
\hline Total & 2 & 2 & 18 & 20 & 15 & 12 & 22 & 91 \\
\hline
\end{tabular}


Table 4 Trade show performance $(n=40)$

\begin{tabular}{|c|c|c|c|c|c|c|c|c|c|}
\hline \multirow[b]{2}{*}{ Performance metrics } & \multirow[b]{2}{*}{ Participation modes } & \multicolumn{7}{|c|}{ Publication period } & \multirow[b]{2}{*}{ Total } \\
\hline & & $\begin{array}{l}1980- \\
1984\end{array}$ & $\begin{array}{l}1985- \\
1989\end{array}$ & $\begin{array}{l}1990- \\
1994\end{array}$ & $\begin{array}{l}1995- \\
1999\end{array}$ & $\begin{array}{l}2000- \\
2004\end{array}$ & $\begin{array}{l}2005- \\
2009\end{array}$ & $\begin{array}{l}2010- \\
2014\end{array}$ & \\
\hline \multirow{5}{*}{$\begin{array}{l}\text { Sales-related } \\
\text { performance }\end{array}$} & Exhibiting mode & - & - & 3 & 4 & 2 & - & - & 9 \\
\hline & Visiting mode & - & - & - & - & - & - & - & - \\
\hline & Organizing mode & - & - & - & - & - & - & 1 & 1 \\
\hline & $\begin{array}{l}\text { A combination of } \\
\text { participation modes }\end{array}$ & - & - & 1 & - & - & - & - & 1 \\
\hline & Total & - & - & 4 & 4 & 2 & & 1 & 11 \\
\hline \multirow{5}{*}{$\begin{array}{l}\text { Behavior-related } \\
\text { performance }\end{array}$} & Exhibiting mode & - & 1 & 2 & 6 & 5 & 5 & 6 & 25 \\
\hline & Visiting mode & - & - & - & - & 1 & - & 2 & 3 \\
\hline & Organizing mode & - & - & - & - & - & - & - & - \\
\hline & $\begin{array}{l}\text { A combination of } \\
\text { participation modes }\end{array}$ & - & - & - & 1 & - & - & - & 1 \\
\hline & Total & - & 1 & 2 & 7 & 6 & 5 & 8 & 29 \\
\hline
\end{tabular}

Table 5 Theoretical perspective $(n=91)$

\begin{tabular}{|c|c|c|c|c|c|c|c|c|}
\hline & \multicolumn{7}{|c|}{ Publication period } & \multirow[b]{2}{*}{ Total } \\
\hline & $\begin{array}{l}1980- \\
1984\end{array}$ & $\begin{array}{l}1985- \\
1989\end{array}$ & $\begin{array}{l}1990- \\
1994\end{array}$ & $\begin{array}{l}1995- \\
1999\end{array}$ & $\begin{array}{l}2000- \\
2004\end{array}$ & $\begin{array}{l}2005- \\
2009\end{array}$ & $\begin{array}{l}2010- \\
2014\end{array}$ & \\
\hline Articles grounded in theory & - & 1 & 7 & 4 & 7 & 7 & 19 & 45 \\
\hline $\begin{array}{l}\text { Articles not grounded in } \\
\text { theory }\end{array}$ & 2 & 1 & 11 & 16 & 8 & 5 & 3 & 46 \\
\hline Total & 2 & 2 & 18 & 20 & 15 & 12 & 22 & 91 \\
\hline
\end{tabular}


Table 6 Theories, conceptual frameworks and models $(n=45)$

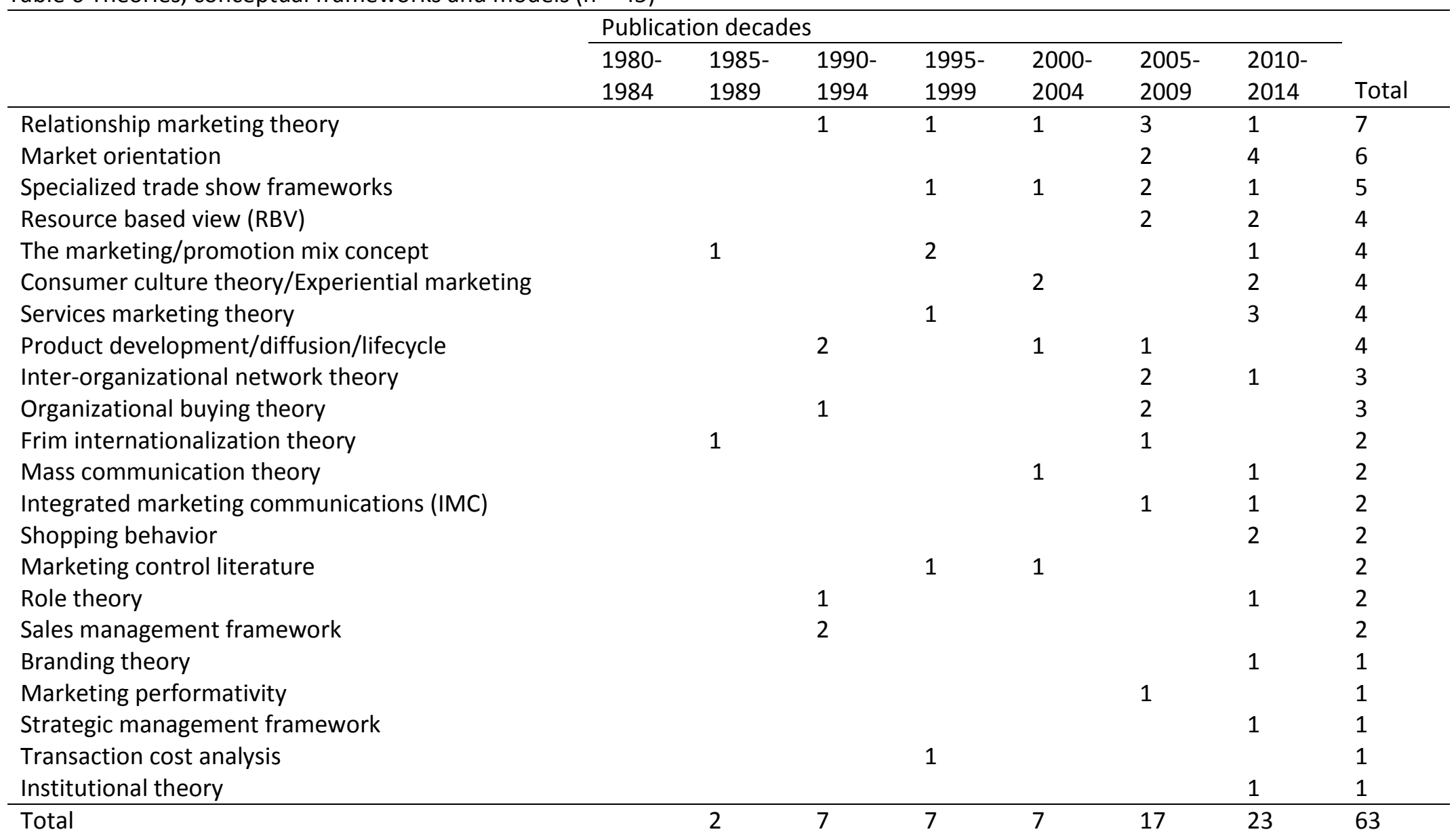


Table 7 Theoretical contribution $(n=91)$

\begin{tabular}{lllllllll}
\hline & \multicolumn{2}{l}{ Publication period } & & & & \\
\cline { 2 - 8 } Types of contribution & $1980-$ & $1985-$ & $1990-$ & $1995-$ & $2000-$ & $2005-$ & $2010-$ & \\
& 1984 & 1989 & 1994 & 1999 & 2004 & 2009 & 2014 & Total \\
\hline Exploratory articles & 2 & - & 13 & 16 & 8 & 2 & 6 & 47 \\
Theory testing articles & - & 2 & 4 & 2 & 3 & 6 & 11 & 28 \\
Theory building articles & - & - & 1 & 2 & 4 & 4 & 5 & 16 \\
\hline Total & 2 & 2 & 18 & 20 & 15 & 12 & 22 & 91 \\
\hline
\end{tabular}

Table 8 Research design $(n=73)$

\begin{tabular}{|c|c|c|c|c|c|c|c|c|}
\hline \multirow[b]{2}{*}{ Types of design approaches } & \multicolumn{7}{|c|}{ Publication period } & \multirow[b]{2}{*}{ Total } \\
\hline & $\begin{array}{l}1980- \\
1984\end{array}$ & $\begin{array}{l}1985- \\
1989\end{array}$ & $\begin{array}{l}1990- \\
1994\end{array}$ & $\begin{array}{l}1995- \\
1999\end{array}$ & $\begin{array}{l}2000- \\
2004\end{array}$ & $\begin{array}{l}2005- \\
2009\end{array}$ & $\begin{array}{l}2010- \\
2014\end{array}$ & \\
\hline Cross-sectional & 1 & 2 & 8 & 13 & 9 & 8 & 13 & 54 \\
\hline Case-study & - & - & 1 & - & - & 3 & 3 & 7 \\
\hline Comparative & - & - & 1 & 3 & 1 & - & 1 & 6 \\
\hline Experimental & - & - & 1 & 1 & 1 & - & - & 3 \\
\hline Longitudinal & - & - & 1 & - & 1 & - & - & 3 \\
\hline Total & 1 & 2 & 12 & 17 & 12 & 11 & 18 & 73 \\
\hline
\end{tabular}


Table 9 Data collection methods $(n=73)$

\begin{tabular}{|c|c|c|c|c|c|c|c|c|}
\hline \multirow[b]{2}{*}{$\begin{array}{l}\text { Types of data collection } \\
\text { methods }\end{array}$} & \multicolumn{7}{|c|}{ Publication period } & \multirow[b]{2}{*}{ Total } \\
\hline & $\begin{array}{l}1980- \\
1984\end{array}$ & $\begin{array}{l}1985- \\
1989\end{array}$ & $\begin{array}{l}1990- \\
1994\end{array}$ & $\begin{array}{l}1995- \\
1999\end{array}$ & $\begin{array}{l}2000- \\
2004\end{array}$ & $\begin{array}{l}2005- \\
2009\end{array}$ & $\begin{array}{l}2010- \\
2014\end{array}$ & \\
\hline Survey & 1 & 2 & 8 & 11 & 7 & 5 & 10 & 44 \\
\hline $\begin{array}{l}\text { Survey combined with other } \\
\text { methods, such as in-depth } \\
\text { interviews and focus group }\end{array}$ & - & - & 3 & 3 & 3 & 3 & 3 & 15 \\
\hline Ethnography & - & - & - & - & 2 & 2 & 2 & 6 \\
\hline Interview & - & - & 1 & 2 & - & 1 & 1 & 5 \\
\hline Secondary data & - & - & - & 1 & - & - & 2 & 3 \\
\hline Total & 1 & 2 & 12 & 17 & 12 & 11 & 18 & 73 \\
\hline
\end{tabular}

